\title{
Gravity experiment faces a three year delay
}

Washington. A revamped proposal for the Laser Interferometer Gravitational-wave Observatory (LIGO) is being backed by the US National Science Foundation (NSF). It will cost 40 per cent more and take three years longer to complete than one endorsed by the science funding agency in 1990 .

The increase in planned costs and timescales are being blamed on 'management failures' resulting from the previous running of the project, compounded by Congress holding up funds as a result. Robbie Vogt, a physicist at the California Institute of Technology (Caltech) and LIGO's founding father, was replaced as project manager in March by Barry Barish, a high-energy physicist with experience in managing large parts of the now-defunct Superconducting Super Collider.

Barish is putting together a LIGO management team, including financial controllers and systems engineers, to ensure that the project is built to its new cost and schedule. Previously, he says, "it was organized in the way you would run a laboratory", with a couple of people in charge and no real structure for delegating responsibility.

The National Science Board, the NSF's governing body, agreed last week to support LIGO on the basis of new estimates of \$297 million to build over seven years - the original estimate was $\$ 212$ million over four years - and another $\$ 69$ million to operate for four years, starting in 1997.

NSF officials will meet congressional staff this week, and are optimistic about securing continued congressional support for the project.

The proposal includes two ground stations, one at Hanford in Washington state, and the other at Livingston Parish in Louisiana. These will use advanced optical techniques to detect the tiny vibrations caused by distant cosmic events.

Neal Lane, director of the NSF, says the decision to proceed "was a very difficult one, because we know that future budgets are tight and that LIGO costs will be higher than originally authorized". Lane refuses to specify which NSF programmes would be cut to meet the extra costs. "It is hard to predict what the trade-off is going to be, but we know there will be a trade-off," he says.

The new money for LIGO includes an extra $\$ 37$ million required to cover the extension of the project by the further three years, \$16 million of extra management costs, $\$ 23$ million to cover new research and construction costs, and \$9 million extra

\section{CORRECTION}

A recent news item (Nature 371, 549; 1994) should have said that the Japanese Meteorological Agency (JMA) is able to provide rapid measurements of the 'intensity' of earthquakes felt in various cities, rather than their 'magnitude'. for contingencies.

LIGO is being built jointly by Caltech and the Massachusetts Institute of Technology. The extension of the project construction timescale has been caused by actual project management problems, compounded by Congress holding up money until the problems were seen to be solved.

LIGO is an all-US project. But physicists hope that its two detectors will be complemented by two others, one in Europe and the other in Australia or Japan. An earlier plan to build a detector near Hannover in Germany hit problems, but an Italian-French collaboration for a detector near Pisa is well advanced.

Earlier this month, Australian physicists expressed disappointment with the amount of support they will get from their government to plan for a detector there (see Nature 372, 121; 1994).

Each LIGO detector will consist of an evacuated, L-shaped pipe, with limbs four kilometres long and one metre in diameter. The detector will work by reflecting highly coherent lasers off mirrors mounted on freehanging weights at the end of each limb. When distant cosmic explosions shake the weights by as little as $10^{-16}$ - one-hundredmillionth of the diameter of a hydrogen atom - interference between the lasers will reveal the movement, scientists say.

Physicists are excited at the prospect of a detector that will either confirm and help to refine Einstein's theory of relativity, or - if it fails to pick anything up - suggest that he was wrong. Astronomers, some of whom feel they already have enough data from optical and radiotelescopes, have been markedly less enthusiastic. But Barish points out that LIGO will open up an entirely new field of astronomy, dependent not on the photon but on its hitherto elusive cousin, the graviton.

\section{Germany links education to science}

Munich. One of the few surprises in Chancellor Helmut Kohl's new cabinet, announced last week, has been the appointment of Jürgen Rüttgers as Germany's new "minister for the future".

Rüttgers takes over the newly created ministry of education, science, research and technology, which will be known as the BMBWFT (Bundesministerium für Bildung, Wissenschaft, Forschung und Technologie). The ministry is a result of a merger between the former education and research ministries, created out of a desire for smaller government.

Even by German standards, the BMBWFT is a bit of a mouth-

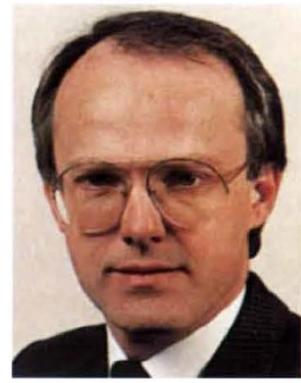
Rüttgers: minister with a future? ful, explaining why its working title presumably now to be dropped - was "ministry for the future". The title also emphasized the raised status of the new ministry; former governments have considered education and research as relatively minor ministries.

Rüttgers, a Christian Democrat who is only $\mathbf{4 3}$ years old, has been a member of the German parliament since 1987. His star has risen rapidly. Although a lawyer with no previous scientific expertise, he immediately joined the parliamentary research committee (1987-90), and from 1987 to 1989 headed the parliamentary inquiry committee whose work led to the establishment of an office for technological assessment.

During his first years in parliament he developed a particular interest in space activities, of which he was generally very supportive. In 1987 he wrote a short guide to Europe's options in space technology. He has been parliamentary whip for the Christian Democrats since 1989.

Acknowledged as both highly intelligent and politically astute, Rüttgers' ap pointment has been welcomed in most quarters. But he is also known to be very ambitious, and newspaper articles have speculated that he may view his new ministry, despite its higher profile, merely as a career steppingstone. If so, he would be following the footsteps of Matthias Wissmann, a former research minister who held office for three months early last year before transferring his portfolio to the ministry for transport.

The BMBWFT will have two parliamentary state secretaries: Bernd Neumann, who held this position in the previous research ministry, will be joined by Cornelia Yzer, who has been transferred from the previous ministry for women and youth.

Both Paul Krüger, the former research minister who comes from east Germany, and Karl-Hans Laermann, the former education minister, have left the cabinet. The former environment minister, Klaus Töpfer, widely expected until the last minute to head the BMBWFT, becomes minister for urban development. He is replaced by Angela Merkels from east Germany.

Alison Abbott 